\title{
Bridging the gap between risk and uncertainty in insurance
}

\author{
Peter Zweifel ${ }^{1}$
}

Accepted: 24 February 2021 / Published online: 7 April 2021

(c) The Author(s) 2021

\begin{abstract}
This contribution evokes Orio Giarini's courage to think 'outside the box'. It proposes a practical way to bridge the gap between risk (where probabilities of occurrence are fully known) and uncertainty (where these probabilities are unknown). However, in the context of insurance, neither extreme applies: the risk type of a newly enrolled customer is not fully known, loss distributions (especially their tails) are difficult to estimate with sufficient precision, the diversification properties of a block of policies acquired from another company can be assessed only to an approximation, and rates of return on investment depend on decisions of central banks that cannot be predicted too well. This contribution revolves around the launch of an innovative insurance product, where the company has a notion of whether a favourable market reception is more likely than an unfavourable one, of the chance of obtaining approval from the regulatory authority and the risk of a competitor launching a similar innovation. Linear partial information theory is proposed and applied as a particular practical way to systematically exploit the imprecise information that may exist for all of these aspects. The decision-making criterion is maxEmin, an intuitive modification of the maximin rule known from games against nature.
\end{abstract}

Keywords Uncertainty · Linear Partial Information · MaxEmin criterion · New insurance product

\section{Introduction and motivation}

The Italian proverb cited above is a fitting motto for Orio's life- - he was always willing to consider a new idea. When, at a European Group of Insurance Economists (EGRIE) meeting, a paper of mine drew criticism, he would say, "At least this piece

Peter Zweifel

peter.zweifel@uzh.ch

1 Emeritus University of Zürich, Wulfensiedlung 24, 9530 Bad Bleiberg, Austria

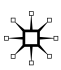


encourages us to think outside the box". As the former manager of a jazz radio station in Trieste (Italy), he arranged for bass and drums to accompany Jim Garven (Baylor University) on the flute and myself on the piano at a short gig at the EGRIE seminar of 1987 in Geneva. That was 'outside the box' too because he had never heard either of us play before.

Orio's heart lay with the more applied contributions that, today, would be published in the Issues \& Practice series of The Geneva Papers. For this reason, this paper is motivated by a practical issue that concerned this author 10 years ago. At the conference, 'Insuring the Health of an Ageing Population' organised by The Geneva Association, the delegate of a U.K. pension insurer described an interesting innovation, which has become known as an enhanced annuity. When the company learns of a serious health condition, it offers the policyholder an extra payment to finance some of the expenditure that is not covered by health insurance. This is feasible because the condition lowers the insured's remaining life expectancy and hence reduces the number of years the annuity has to be paid. When this innovation was reported by this author in the newspaper Neue Zürcher Zeitung (NZZ), no fewer than three managers representing different divisions of the same (!) insurer called, keen to know details. At a quickly arranged meeting, they committed to reaching a decision within three months as to whether their company would launch a similar innovation. Well, as stated above, this was 10 years ago, and the company is still deciding...

Admittedly, launching an innovation in insurance is not easy. It is more than risky. It is uncertain because crucial probabilities are not sufficiently known:

- The new product may attract unfavourable risks, aggravating the adverse selection problem. In the example cited above, the condition causing the reduction in remaining life expectancy might be negatively correlated with other health conditions, which counteract the shortening of life expectancy. However, if all we know is that the coefficient of correlation is less than 0.5 (say), the information is too weak to be of value in conventional approaches.

- In non-life insurance, very high losses are too rare to enable estimation of their probability of occurrence with a sufficient degree of precision. This means that reserves allocated to that particular line are insufficient with a probability of at least 5\% (say); again, very weak information.

- Sometimes, a block of policies can be acquired from another company. The issue then arises as to whether these policies increase overall risk exposure or help diversify risk. The information available suggests that risk diversification is more probable than increased risk exposure; this is not sufficient to reach a wellfounded decision.

- For the bottom line, the rate of return that can be achieved on capital investment is crucial. Forward guidance by the Federal Reserve and the European Central Bank may be lacking, as these institutions do not firmly commit to a future policy. However, they may indicate that a continuation of their zero interest rate policy is not very likely (say); once again, weak information. 
All these instances are subject to at least partial uncertainty in the sense of Knight (1921), who first distinguished between risk and uncertainty. In the case of risk, probabilities are known; in the case of complete uncertainty, they are unknown. However, in many cases relevant for insurance, experience and research yield at least some information, which arguably can and should be exploited for decision-making.

In the case of true uncertainty, one is thrown back to following Wald (1945), who viewed nature as an adversary to human decision-makers. In this situation, only the pessimistic maximin decision rule appropriate for zero-sum games can be applied. If at least the intervals in which the payoffs (i.e. the outcomes expressed in money units) lie are known with certainty, the Hurwicz criterion (Hurwicz 1951) is recommended. It proposes using a linear combination of the maximin and the maximax values, with the weight of the maximax value (the highest of all possible maxima) reflecting the decision-maker's degree of optimism. ${ }^{1}$ The downside of this alternative is that the optimism parameter is purely subjective.

Rather than discussing additional decision-making criteria [see Gilboa (2013), in particular chapters 7 and 15-17 for a survey], this contribution presents the theory of linear partial information (LPI) as a way to bridge the gap between uncertainty and risk. LPI theory, pioneered by Kofler and Menges (1977), can deal with any linear information about probabilities and payoffs (imprecise intervals can be expressed in terms of restrictions on probabilities) and does not require any subjective weighting parameter. The price to be paid is the assumption that the decision-maker is engaged in a game against nature. Since her survival is assured, nature need not be fully adversarial by always choosing the outcome that inflicts maximum loss on the decision-maker. Nature is adversarial to the extent that she presents the decision-maker with the urn containing the probability distribution with the minimum expected payoff. Accordingly, the LPI decision rule is the maxEmin criterion, a natural relaxation of Wald's maximin criterion.

Kofler and Menges (1977) were able to show that a piece of information regarding probabilities of possible outcomes such as $r_{1} \geq r_{3}$ (with $r_{1}+r_{2}+r_{3}+\cdots r_{\mathrm{n}}=1$ ) can be systematically exploited for decision-making. LPI theory has led to a series of publications, notably by Kofler and Menges (1979), Kofler (1988) and Kofler and Zweifel (1988, 1991, 1993).

LPI theory is just one alternative for dealing with what is commonly called ambiguity. A natural idea is to define probabilities over probabilities, e.g. over $r_{1}$, such as $\operatorname{Prob}\left(r_{1}=0.9\right)=0.1, \operatorname{Prob}\left(r_{1}=0.8\right)=0.1, \operatorname{Prob}\left(r_{1}=0.7\right)=0.2, \operatorname{Prob}\left(r_{1}=0.6\right)=0.3$, etc. The resulting unambiguous probability distribution, e.g. $r_{1}=0.7, r_{2}=0.3$, could then be used to calculate the insurer's expected profit. However, actual decisionmakers were soon found to evaluate the original compound lottery in a different way from the reduced one (Bar-Hillel 1973). This finding led to an extended literature on the axioms necessary to preserve the equivalence between the two settings and the importance of ambiguity aversion in the event these axioms are not satisfied. An

\footnotetext{
1 The Hurwicz criterion can be used to explain why consumers often purchase full insurance despite the fact that premiums contain a positive proportional loading, contrary to conventional theory based on expected utility (Briys and Loubergé 1985).
} 
elegant solution was proposed by Klibanoff et al. (2005), who introduce two transformations. One is the well-known risk utility function, which reflects the probabilities, the other, a transformation defined over these probabilities, reflects the decision maker's ambiguity aversion. Yet, as the authors' (Klibanoff et al. 2012) lengthy reply to a critique by Epstein (2010) shows, the construction of the convolution of these two transformations is anything but straightforward. As will become evident in the next section, LPI theory offers a much simpler, practical alternative.

\section{Applying LPI theory to a decision-making situation at an innovating insurance company}

In this contribution, LPI theory is applied to the decision-making situation of an insurance company that considers launching a new product such as the pension plan with payment adjusted for changes in remaining life expectancy described in the previous section (see Fig. 2 below for the pertinent decision tree).

\section{Calculating the minimum expected payoff if the innovation is launched}

As always, the decision tree is solved backwards, starting with its upper branch where the insurance company (IC for short) launches the innovation. At the market level, let $r_{1}$ =probability of a favourable reception of the innovation, $r_{2}=$ probability of a neutral reception, and $r_{3}=$ probability of an unfavourable reception. If the regulatory authority $\mathrm{R}$ approves and competitor $\mathrm{C}$ abstains from launching its own innovation, then let the respective payoffs be USD million $\{100,50,10\}$ in present value terms. ${ }^{2}$ These figures are realistic in view of the fact that the annual premium incomes of major insurers are in USD tens of billions (Statista 2019).

As to the probabilities, let the only available information be $r_{1} \geq r_{3}$, which precludes calculation of an expected payoff value using traditional approaches. However, LPI can be used to calculate the so-called maxEmin value as a guide for decision-makers, as will be shown below.

The first step is to identify the relevant probability distributions. In the left-hand panel of Fig. 1, each point on the triangular plane defined by $r_{1}+r_{2}+r_{3}=1$ reflects a distribution. The shaded triangular plane represents those distributions which satisfy the restriction, $r_{1} \geq r_{3}$. In the right-hand panel, the same plane is shown as a triangle confined by the vertices ABD. Evidently, all points contained in the triangular area ABD represent distributions that satisfy $r_{1} \geq r_{3}{ }^{3}$ Note that this set is still infinite.

\footnotetext{
${ }^{2}$ Uncertainty concerning the values of these payoffs can be introduced as well, e.g. by LPI: $q_{1}(50<P>1$ $00)<q_{2}(10<P<50), q_{1}+q_{2}=1$, with $q_{1}$ and $q_{2}$ denoting probabilities and $P$ denoting the payoff.

3 For a generalisation to $n$-dimensional space, see the theorem in Hadley $(1961,179)$. It states that a system of $k$ inequalities must satisfy $k$ restrictions (including the summation restriction) as equalities for obtaining a base in a linear programme and hence a vertex point.
} 


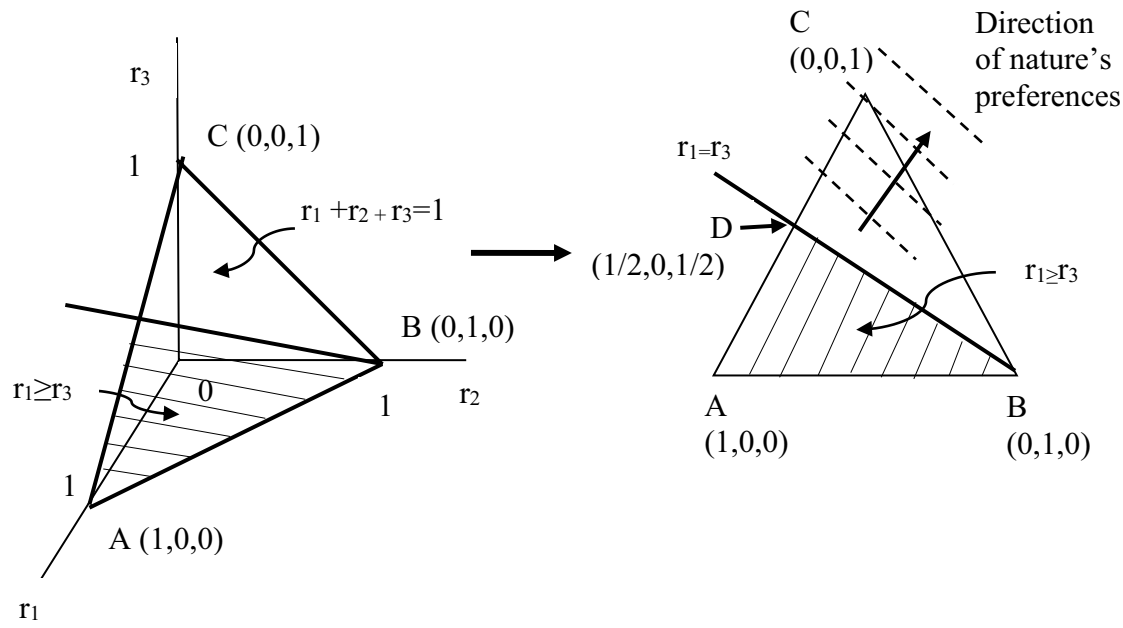

Fig. 1 The set of relevant probability distributions in three-dimensional and two-dimensional space

However, it can be reduced to a finite number of elements at the price of the following assumption. The decision-maker is engaged in a game against nature, which is zero-sum in expected values, calling for application of the maxEmin decision rule.

The maxEmin criterion is an intuitive generalisation of the pessimistic maximin criterion, where the decision-maker assumes that nature (or an adversary more generally) always chooses the action which has minimum payoff to him or her. Applying Wald's (1945) maximin criterion ensures the decision-maker's survival in a fully hostile environment. However, nature, acting as one's adversary, will always survive so has no need to consistently opt for the action inflicting the greatest possible loss to the human decision-maker. Rather, she can afford to confront him or her with the probability distribution giving rise to the minimum expected payoff. Among these relevant distributions, the decision-maker can opt for the one that guarantees the maximum payoff on expectation through his or her choice of action. This amounts to applying the maxEmin criterion.

Applying the maxEmin criterion has a crucial benefit. Since nature can be assumed to be risk neutral, her preferences are in terms of expected values, which are linear functions of probabilities. This makes her indifference curves linear, as shown by the dashed lines on the right-hand side of Fig. 1. However, she cannot reach point $\mathrm{C}$ with the distribution $(0,0,1)$ in view of the LPI: $r_{1} \geq r_{3}$. Her optimum cannot be in the interior of $\mathrm{ABD}$ either but must lie at one of its vertices ABD. ${ }^{4}$ This follows from the fundamental equivalence between a zero-sum game and a linear programme (Chiang 1984, Sect. 21.4). The optimum solution to a linear programme

\footnotetext{
4 Since nature's preferences are linear, the decision-maker's solution to the linear programme (see fn. 3) corresponds to nature's solution of the dual due to the equivalence of a zero-sum game and a linear programme. Therefore, nature necessarily selects a vertex point (Intriligator 1971, p. 75).
} 


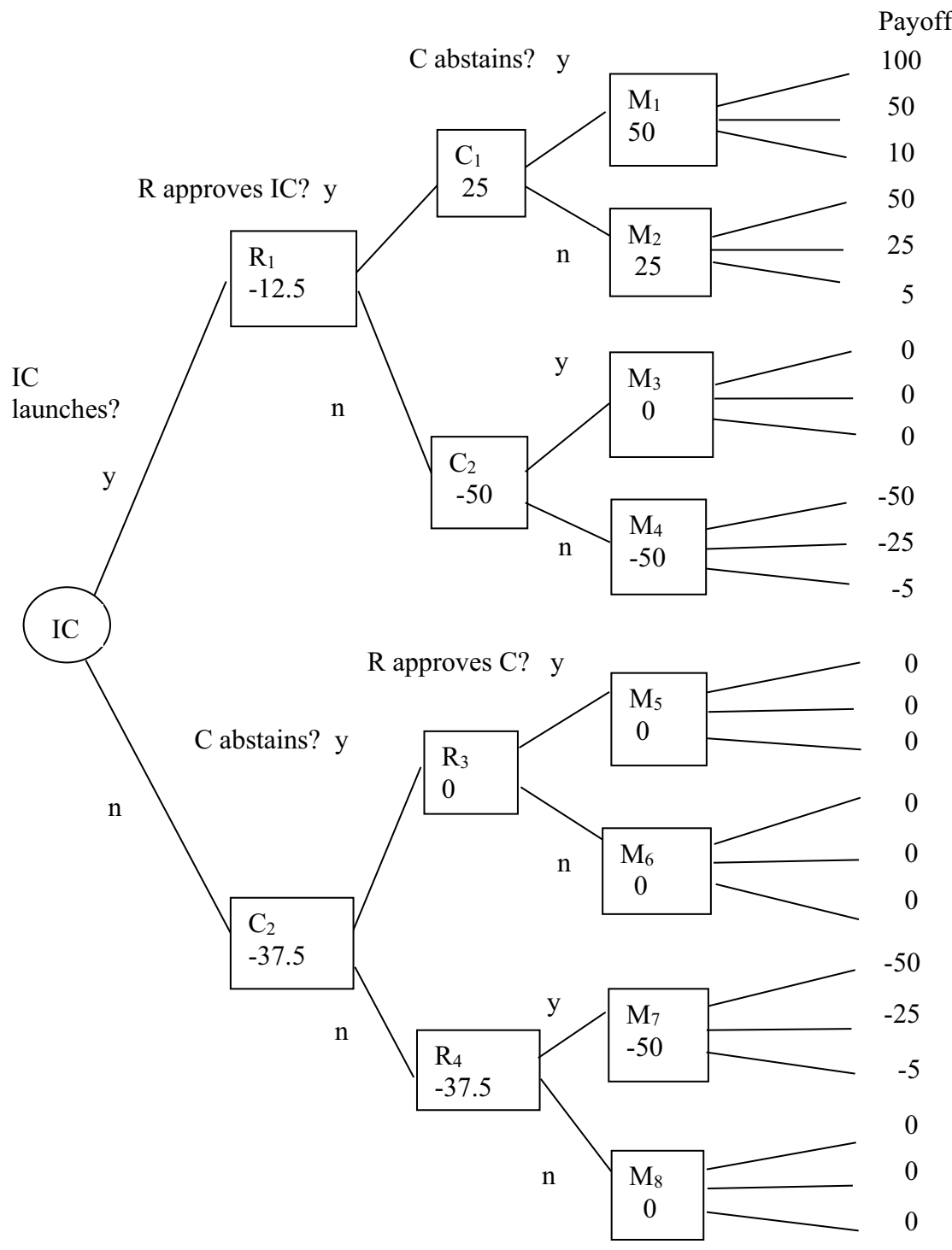

Fig. 2 Decision-making situation at the innovating insurance company

is given by one of the extreme points of the feasible region (Chiang 1984, Theorem II in Sect. 18.3). These extreme points (vertices) satisfy the condition that for a $k$-dimensional feasible space, the number of restrictions satisfied as exact equalities is also $k$ (Chiang 1984, Sect. 18.4; also see fn. 3).

In the present context, $n=3$; therefore, it is sufficient to consider the vertices $\mathrm{A}, \mathrm{B}$ and $\mathrm{D}$, where the restrictions $r_{1} \geq r_{3}$ and $r_{1}+r_{2}+r_{3}=1$ are satisfied as equalities. The 
vertices characterising the relevant probabilities at the market level can be assembled in the matrix $V[M]$ :

$$
V[M]=\left[\begin{array}{lll}
1 & 0 & 1 / 2 \\
0 & 1 & 0 \\
0 & 0 & 1 / 2
\end{array}\right]
$$

(A) (B) (D)

Hence, the relevant expected payoffs $E P$ at node $M_{1}$ of Fig. 2 are (minimum underscored)

$$
E P\left[M_{1}\right]=\left[\begin{array}{lll}
100 & 50 & 10
\end{array}\right]\left[\begin{array}{lll}
1 & 0 & 1 / 2 \\
0 & 1 & 0 \\
0 & 0 & 1 / 2
\end{array}\right]=\left[\begin{array}{lll}
100 & 50 & 55
\end{array}\right]
$$

Given that nature is antagonistic, she will choose the distribution associated with the minimum expected payoff. The value of the game to the decision-maker (prior to deducting the outlay on product development) is therefore USD 50 million (entered at node $M_{1}$ in Fig. 2).

However, C may launch a similar innovation of its own. In that event, a standard assumption is that the market is split in half between the two competitors as long as their products are not strongly differentiated, following Hotelling (1929) and Salop (1979). Therefore, payoffs to the IC are reduced to USD million $\{50$, $25,5\}$, giving rise to expected payoffs at node $M_{2}$

$$
E P\left[M_{2}\right]=\left[\begin{array}{lll}
50 & 25 & 5
\end{array}\right]\left[\begin{array}{lll}
1 & 0 & 1 / 2 \\
0 & 1 & 0 \\
0 & 0 & 1 / 2
\end{array}\right]=\left[\begin{array}{lll}
50 & 25 & 27.5
\end{array}\right]
$$

with a minimum value of USD 25 million.

To calculate the minimum expected value of its payoff at node $C_{1}$, the IC needs an estimate of the likelihood of $\mathrm{C}$ successfully launching an innovation of its own. This is strategic information that is not easy to come by. So, let the best estimate be at least $80 \%$ probability of $\mathrm{C}$ going ahead, implying $s_{\mathrm{a}}<0.2$ for abstention. In the left panel of Fig. 3, the pertinent vertices $C, B$ and $D$ are shown in two-dimensional space; in the right panel, they appear in one-dimensional space. Therefore, the relevant vertices are given by

$$
V[M]=\left[\begin{array}{ll}
0 & 0.2 \\
1 & 0.8
\end{array}\right]
$$

(B) (D)

Therefore, one obtains the expected payoffs to the IC 
Fig. 3 The set of relevant probability distributions at point $C_{1}$ of Fig. 2, $s_{\mathrm{a}}<0.2$

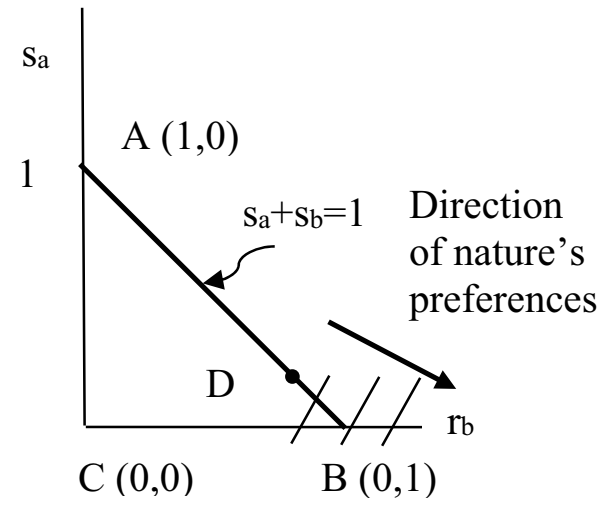

with the minimum equal to USD 25 million. The qualification 'successfully' points to a shortcut in the analysis. In fact, $\mathrm{C}$ also needs to obtain approval by $\mathrm{R}$, which is uncertain. However, in the spirit of the maxEmin principle, approval is taken as a given, constituting the worst-case scenario for the IC.

Up to this point, the regulatory authority $\mathrm{R}$ was assumed to approve the IC's innovation. Even if $\mathrm{C}$ abstains from launching its own innovation, the IC will have no extra premium income if approval is denied. With payoffs equal to zero, the expected values of the game at node $M_{3}$ are given by

$$
E P\left[M_{3}\right]=\left[\begin{array}{lll}
0 & 0 & 0
\end{array}\right]
$$

with the minimum equal to zero. However, $\mathrm{C}$ might come up with its own innovation; if $\mathrm{C}$ is of a similar size as the IC and obtains approval, it will garner the same payoffs in USD million $\{100,50,10\}$ as the IC. According to the Hotelling-Salop rule, one half amounts to forgone premium income for the IC, which constitutes an opportunity cost to it. Using the same vertices as in Eq. (1), one thus obtains the expected payoffs to the IC at node $M_{4}$

$$
E P\left[M_{4}\right]=\left[\begin{array}{lll}
-50-25-5 & -5
\end{array}\left[\begin{array}{lll}
1 & 0 & \multicolumn{1}{l}{1 / 2} \\
0 & 1 & 0 \\
0 & 0 & 1 / 2
\end{array}\right]=\left[\begin{array}{lll}
-\underline{-5}-25 & -27.5
\end{array}\right]\right.
$$

with a minimum of USD - 50 million.

For calculating expected payoffs at node $C_{2}$, where approval of its new product is denied, the IC needs to take into account that this failure will encourage competitor $\mathrm{C}$ to go ahead. Still, there may be considerations preventing $\mathrm{C}$ from proceeding, resulting in a probability of launch of less than one. Assuming that the probability of abstention $s_{\mathrm{a}}^{\prime}$ is less than $10 \%$ in this situation, one has the restrictions $s_{\mathrm{a}}^{\prime}<0.1$ and $s_{\mathrm{a}}^{\prime}+s_{\mathrm{b}}^{\prime}=1$. Therefore, the vertices at node $C_{2}$ are, in analogy to Fig. 3, 


$$
V\left[C_{2}\right]=\left[\begin{array}{ll}
0 & 0.1 \\
1 & 0.9
\end{array}\right]
$$

giving rise to relevant expected payoffs

$$
E P\left[C_{2}\right]=\left[\begin{array}{ll}
0 & -50
\end{array}\right]\left[\begin{array}{ll}
0 & 0.1 \\
1 & 0.9
\end{array}\right]=\left[\begin{array}{ll}
-50 & -45
\end{array}\right]
$$

and a minimum value of USD - 50 million at node $\mathrm{C}_{2}$.

Next, the IC has to gauge the likelihood of attaining approval by the regulatory authority R. An important consideration in the present context is that the IC needs information from a health insurer concerning the occurrence of the condition and its precise nature in order to estimate the reduction in remaining life expectancy. However, health insurance is at least as strictly regulated as pension insurance, making approval uncertain. For concreteness, let the perceived likelihood of approval be between $50 \%$ and $75 \%$, respectively. With the pertinent vertices, one obtains expected payoff values at node $r_{1}$

$$
E P\left[R_{1}\right]=[25-50]\left[\begin{array}{ll}
0.5 & 0.75 \\
0.5 & 0.25
\end{array}\right]=\left[\begin{array}{ll}
-12.5 & 6.25
\end{array}\right]
$$

Therefore, the minimum expected payoff pertaining to the upper branch of the decision tree in Fig. 2 (launch) amounts to USD - 12.5 million. It should be noted that this is an assured minimum payoff from the product innovation, but still in terms of expected value.

The lower branch of Fig. 2 is evaluated in the Appendix. The guaranteed expected payoff in the case that the innovation is not launched amounts to USD -37.5 million.

\section{Applying the maxEmin decision rule}

Under the maxEmin decision rule introduced in the previous section, the optimal decision for the IC is unambiguous, in spite of the imprecise value of the probabilities involved. It makes sense to launch the innovation and to incur an expected negative payoff of USD - 12.5 million unless product development costs at least USD 25 million because not launching the innovation would be associated with an even greater loss of USD - 37.5 million. It is therefore preferable to launch the innovation.

Evidently, the same type of LPI procedure can be applied to the other problems confronting insurers cited in the Introduction.

\section{Limitations and extensions of LPI theory}

The most important limitation of LPI theory is the lack of evidence concerning application of the maxEmin decision rule. Other criteria that do not rely on knowledge of probabilities (contrary to expected utility theory) have been 
examined, at least experimentally. While Wald's (1945) maximin rule does not seem to have been confronted with empirical evidence, the less pessimistic maximin regret rule has been at least partially confirmed by Zeelenberg and Pieters (2004) and Filiz-Ozbay and Ozbay (2007) in the context of auctions. There, the successful bidder often realises that he or she paid too much, motivating the minimisation of the maximum divergence between his or her decision and the truly optimal one (Niehans 1948; Savage 1951).

Another approach to partial information regarding probabilities and payoffs is ambiguity (Schmeidler 1989). The effect of ambiguity on decision-making has been confirmed experimentally by Kelsey and le Roux (2018) in the context of the so-called battle of the sexes, a two-person zero-sum game. Avoidance of ambiguity is shown to have positive value to the players. Arguably, this provides indirect support to LPI theory, which provides a measure of the value of information (and hence willingness to pay for the avoidance of ambiguity). To illustrate, let it be known that the probability of the IC obtaining regulatory approval is precisely $75 \%$ rather than between $50 \%$ and $75 \%$ (for simplicity, minimum expected payoffs are retained at $M_{1}$ to $M_{4}$ as well as $C_{1}$ and $C_{2}$ ). Then, the expected payoff at node $r_{1}$ amounts to

$$
E P^{\prime}\left[R_{1}\right]=[25-50]\left[\begin{array}{l}
0.75 \\
0.25
\end{array}\right]=6.25
$$

Evidently, the removal of ambiguity would turn the innovation into a profitable investment in expected value terms. Under the maxEmin rule, the avoidance of ambiguity is worth USD 6.25 million $[=6.25-(-12.5)]$ on expectation.

As to extensions, LPI theory allows one to render all the elements of the decision tree of Fig. 2 uncertain or more uncertain. Starting with the payoffs, the figure 100 at the top can be replaced by e.g. $\{110,90\}$ with probabilities $q_{1}$ and $q_{2}$, where $2 q_{1}<q_{2}$ (say). In Fig. 2, this would call for a set of additional nodes under the control of nature with vertices $\left\{[1 / 3,2 / 3]^{\prime},[0,1]^{\prime}\right\}$. Of course, uncertainty with regard to the development cost of the new product can be introduced in the same way.

Next, there may be several sources of information characterised by their respective credibility, as in Kofler and Zweifel (1988). For instance, a market research firm might come up with the pessimistic prediction $r_{1}<r_{3}$, indicating that an unfavourable market response is more likely than a favourable one. The management of the IC then needs to come up with a (usually rather subjective) estimate of the likelihood that this information, rather than the original, is true. Typically, this estimate will be in the guise of an LPI associated with still another set of nodes under the control of nature. The dynamic integration of new information can also be modelled as a Bayesian process resulting in an a priori and an a posteriori LPI, as in Kofler and Zweifel (1993).

In addition, there may be more than one competitor, each characterised by its own LPI regarding the probability of launching an innovation. This calls for the convolution of LPIs at node $C_{1}$ in Fig. 2, as expounded in Kofler and Zweifel (1991). Finally, the IC may consider investing its funds in something else, giving rise to an entire decision tree of its own. This alternative will also typically be fraught with 
uncertainties, which can be modelled using LPI theory and calls for a whole set of convolutions.

\section{Concluding remarks}

This contribution is clearly 'outside the box' of risk theory and the economics of insurance but it might have pleased Orio Giarini. It proposes the analysis of LPI in a situation between uncertainty, defined as partial or complete ignorance of probabilities of occurrence, and risk, where probabilities are known to the decision-maker. The example used is that of an insurance company that considers launching an innovative product but cannot gauge precisely the likelihood of a favourable reception by the market, the probability of a competitor launching its own innovation or the chance of approval by the regulatory authority. Nevertheless, LPI theory provides ambiguous advice to the management of the company-provided they are prepared to accept the so-called maxEmin criterion in a game against nature. The assumption is that nature presents humans with the probability distribution entailing the maximum expected payoff to herself and hence the minimum payoff to the decision-maker. The decision-maker in turn opts for the action that maximises his or her expected payoff.

LPI theory can be extended to cover ambiguity with regard to payoffs to and costs of an innovation, integrating additional information of limited credibility, learning from it, ambiguity with regard to the number of competitors and their intentions, and investment in another possible project with uncertain prospects. The one element currently lacking is experimental evidence concerning the actual use of the maxEmin principle, comparing it to expected utility (profit, respectively), maximin regret and maximin decision rules. Hopefully this contribution will motivate future research in this direction!

\section{Appendix}

This appendix contains the calculations pertaining to the lower branch of Fig. 2, where the IC decides not to launch the new product. In this case, the next move pertains to $\mathrm{C}$, who decides whether or not to launch its own.

Starting to solve the decision tree at the market level again, note that if competitor $\mathrm{C}$ abstains from launching as well, approval of its innovation by $\mathrm{R}$ does not matter from the IC's point of view. Since both extra and forgone premium income accruing to the IC are zero at nodes $M_{5}$ and $M_{6}$, the expected payoffs at node $R_{3}$ are

$$
E P\left[R_{3}\right]=\left[\begin{array}{ccc}
0 & 0 & 0 \\
-- & &
\end{array}\right]
$$

with a minimum of zero.

At node $M_{7}$, competitor $\mathrm{C}$ has obtained approval for its product. The situation for the IC is similar to that at $M_{4}$, the difference being that at $M_{4}$ the IC launches its 
innovation but fails to obtain approval by the regulatory authority R. From the consumer's point of view, this difference is unlikely to matter, which justifies entering the same payoffs and using the same vertices. Expected payoffs to the IC are therefore given by

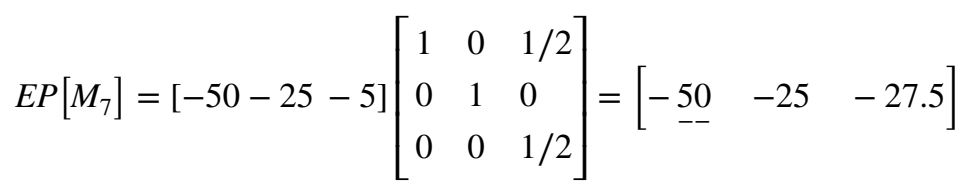

with a minimum of USD - 50 million.

However, R may deny approval to $\mathrm{C}$. In that event, the IC is unaffected, regardless of reception by the market, causing expected payoffs at $M_{8}$ to be

$$
E P\left[M_{8}\right]=\left[\begin{array}{ccc}
0 & 0 & 0 \\
-- & &
\end{array}\right]
$$

with the minimum equal to zero.

Assuming that $\mathrm{R}$ treats the two competitors equally, the probability of approval again lies between $50 \%$ and $75 \%$ as at node $r_{1}$, giving rise to expected payoffs at $R_{4}$ of

$$
E P\left[R_{4}\right]=\left[\begin{array}{ll}
-50 & 0
\end{array}\right]\left[\begin{array}{lll}
0 & .5 & 0.75 \\
0.5 & 0.25
\end{array}\right]=\left[\begin{array}{ll}
-25 & -37.5
\end{array}\right]
$$

For the IC, the value of the game at node $R_{4}$ therefore amounts to USD -37.5 million.

Given that the IC decides not to launch its innovation, there is little to prevent $\mathrm{C}$ from going ahead. Arguably, its propensity to act is the same at node $C_{2}$, where the IC failed to obtain regulatory approval. Using the same vertices, one has

$$
E P\left[C_{3}\right]=\left[\begin{array}{ll}
-37.5 & 0
\end{array}\right]\left[\begin{array}{ll}
1 & 0.9 \\
0 & 0.1
\end{array}\right]=\left[\begin{array}{ll}
-37.5 & -33.75
\end{array}\right]
$$

with the minimum expected payoff to the IC amounting to USD -37.5 million.

Acknowledgements This text benefited greatly from comments and suggestions made by the two Editors of this special issue.

Funding Open Access funding provided by Universität Zürich.

Open Access This article is licensed under a Creative Commons Attribution 4.0 International License, which permits use, sharing, adaptation, distribution and reproduction in any medium or format, as long as you give appropriate credit to the original author(s) and the source, provide a link to the Creative Commons licence, and indicate if changes were made. The images or other third party material in this article are included in the article's Creative Commons licence, unless indicated otherwise in a credit line to the material. If material is not included in the article's Creative Commons licence and your intended use is not permitted by statutory regulation or exceeds the permitted use, you will need to obtain permission directly from the copyright holder. To view a copy of this licence, visit http://creativecommons.org/licen ses/by/4.0/. 


\section{References}

Bar-Hillel, M. 1973. On the subjective probability of compound events. Organizational Behavior and Human Performance 9 (3): 396-406.

Briys, E.P., and H. Loubergé. 1985. On the theory of rational insurance purchasing: a note. Journal of Finance XL (2): 577-581.

Chiang, A.C. 1984. Fundamental methods of mathematical economics, 3rd ed. Tokyo: McGraw-Hill.

Epstein, L.G. 2010. A paradox for the "smooth ambiguity" model of preferences. Econometrica 73 (6): 2085-2099.

Filiz-Ozbay, E., and E.Y. Ozbay. 2007. Auctions with anticipated regret: Theory and experiment. American Economic Review 97 (4): 1407-1418.

Gilboa, I. 2013. Theory of decision under uncertainty. Cambridge, MA: Cambridge University Press.

Hadley, G. 1961. Linear algebra. Reading, MA: Addison-Wesley.

Hotelling, H. 1929. Stability in competition. Economic Journal 39 (153): 41-57.

Hurwicz, L. 1951. The generalized Bayes minimax principle: A criterion for decision making under uncertainty. Cowles Commission Discussion Paper: Statistics No. 335.

Intriligator, M.D. 1971. Mathematical optimization and economic theory. Englewood Cliffs, NJ: Prentice-Hall.

Kelsey, D., and S. le Roux. 2018. An experimental study on the effect of ambiguity in a coordination game. Theory and Decision 84 (3/5): 387-404.

Klibanoff, P., M. Marianacci, and S. Mukerji. 2005. A smooth model of decision making under ambiguity. Econometrica 73 (6): 1849-1892.

Klibanoff, P., M. Marianacci, and S. Mukerji. 2012. On the smooth ambiguity model: A reply. Econometrica 80 (3): 1303-1321.

Kofler, E. 1988. Linear partial information with applications in fuzzy sets and systems. Amsterdam: Elsevier-North-Holland.

Kofler, E., and G. Menges. 1977. Stochastic linearisation of indeterminateness. In Mathematical economics and game theory, ed. R. Henn and O. Moeschlin, 20-63. Berlin: Springer.

Kofler, E., and G. Menges. 1979. The structuring of uncertainty and the maxEmin principle. Operations Research Verfahren 34: 223-234.

Kofler, E., and P. Zweifel. 1988. Exploiting linear partial information for optimal use of forecasts - With an application to U.S. economic policy. International Journal of Forecasting 4: 15-32.

Kofler, E., and P. Zweifel. 1991. Convolution of fuzzy distributions in decision-making. Statistical Papers/Statistische Hefte 32: 123-136.

Kofler, E., and P. Zweifel. 1993. One-shot decisions under linear partial information. Theory and Decision 34: 1-20.

Knight, F.H. 1921. Risk, uncertainty, and profit. Boston, MA: Hart, Schaffner \& Marx.

Niehans, J. 1948. Zur Preisbildung bei ungewissen Erwartungen (On the formation of price under uncertain expectations). Schweizerische Zeitschrift für Volkswirtschaft und Statistik (Swiss Journal of Economics and Statistics) 84 (5): 433-456.

Salop, S.C. 1979. Monopolistic competition with outside goods. Bell Journal of Economics 10 (1): 141-156.

Savage, L.J. 1951. The theory of statistical decision. Journal of the American Statistical Association 46 (253): 55-67.

Schmeidler, D. 1989. Subjective probability and expected utility without additivity. Econometrica 57 (3): 571-587.

Wald, A. 1945. Statistical decision functions which minimize the maximum risk. The Annals of Mathematics 46 (2): 265-280.

Statista. 2019. Leading global insurance companies worldwide in 2019, by revenue. https://www.statista. com/statistics/185746/revenue-of-the-leading-global-insurance-companies/.

Zeelenberg, M., and R. Pieters. 2004. Consequences of regret aversion in real life: The case of the Dutch postcode lottery. Organizational Behavior and Human Decision Processes 93 (2): 155-168.

Publisher's Note Springer Nature remains neutral with regard to jurisdictional claims in published maps and institutional affiliations. 


\section{About the author}

Peter Zweifel is a Professor Emeritus of Economics, Department of Economics, University of Zurich (Switzerland). He has been a visiting professor to the University of California at Santa Barbara, the Wharton School of the University of Pennsylvania, Duke University, Whitwatersrand University in Johannesburg (South Africa), the African Institute of Mathematical Science in Muizenberg/Cape Town (South Africa), Curtin University and University of Western Australia in Perth, Australian National University in Canberra, and the University of New South Wales in Sydney. He received his M.A. (1969) and Ph.D. (1973) in economics from the University of Zurich, followed by a stay as an honorary fellow with the Economics Department of the University of Wisconsin (Madison). Prof. Zweifel is co-author of the textbooks Health Economics, Insurance Economics and Energy Economics and has also published more than 170 articles in refereed journals. From 1997 to 2006, he served as a member of the Swiss Antitrust Authority and from 2006 to 2010 as an advisor to the World Bank. Together with Mark Pauly (Wharton School), he is the founding editor of the International Journal of Health Economics and Management. After his retirement in 2011, he continues to do research and teaching at universities in Australia, China and the Diplomatic Academy in Vienna. Currently, his research mainly revolves around insurance and its regulation, innovation in insurance, the production of health, and technological change in medicine. 